\title{
Information Technology in the 1990s: More Footloose or More Location-bound?
}

\author{
Jungyul Sohn \\ jsohn@ursp.umd.edu \\ Faculty Research Associate \\ National Center for Smart Growth \\ Research and Education \\ 0117 Caroline Hall \\ University of Maryland \\ College Park, MD 20742 \\ TEL. (301) 405-8250 \\ FAX (301) 314-9897
}

\begin{abstract}
This paper examines if information technology has worked towards dispersion or concentration of economic activities in two steps of analysis. The first analysis using locational Gini coefficient and Moran's I focuses on distribution of the urban area as a whole and finds that dispersion was prominent over the years. The second analysis using $G_{i}{ }^{*}$ statistic as the dependent variable in the regression model, however, shows that the technology has induced more concentration rather than dispersion at an intrametropolitan scale, reflecting that there is a discrepancy in the results of the two analyses depending on the spatial scale of the analysis.
\end{abstract}

JEL classification: R1, R3

Keywords : information technology, spatial distribution, concentration, dispersion, Washington-Baltimore CMSA

July 2002 


\section{Introduction}

While information technology (IT) can be defined in a number of different ways, it is generally considered as the technology to overcome distance barrier. People don't have to travel by themselves to communicate with others if they have another way of interaction that does not require physical movement. Traditionally, telephone and fax used to be a few examples of those technologies. Internet, email, and wireless equipments are only a few of the most cutting-edge technologies in this category.

It is not clear, however, if relieving such burden of distance is directly associated with relieving locational constraints of people and their activities. While it is obvious that the technology has a substantial influence on location behavior and distribution pattern of activities, the direction of the impact still needs to be clarified. As a matter of fact, there has been a huge debate on the spatial implication of IT for the past few decades; whether or not it induces a dispersion of economic activities. Supporters of the IT impact on dispersion believe that a reduced significance, if not the demise, of distance will eventually lessen the dependence on locational factors, so that it may work as an alternative to urban congestion problems and/or agglomeration diseconomies. Supporters of the other side of the story insist that it is only a myth to believe that IT induces dispersion. They think that, regardless of the observable influence, some locational constraints will still remain as significant as before; geography still matters even in the new IT society.

Considering a large number of studies addressing this issue at a conceptual level, there have only been a small number of empirical works found to examine this causal 
relationship even if the number has risen in recent years. One of the major reasons behind this trend is the difficulty in obtaining adequate data on IT. The purpose of this study is to examine the proposition at an empirical level to check if the technology has worked in favor of dispersion or concentration of economic activities, especially focusing on some manufacturing sectors. The next section discusses spatial implication of the technology along with the dispersion/concentration propositions addressed. Section 3 deals with the main framework of the empirical analysis and findings are reported in section 4. Section 5 concludes the paper with some policy implications.

\section{Does IT induce dispersion?}

While there have been a number of different types of studies that focus on the new technology and its spatial implication, the fundamental question under those works has been whether IT has any impact on spatial structure in an urban area, i.e. urban form, and if it does, whether or not it induces dispersion of urban activities. There are two major urban activities of interest that have a greater influence on the spatial structure: economic and residential. Urban economic and residential spatial structure can be interpreted as the spatial distribution pattern of those activities. It can be disaggregated into the location decision patterns of individual urban agents such as establishments or households. In turn, an aggregation of those location behaviors should be equal to the overall distribution pattern. As the factors that have an influence on residential location decision are different from the ones on industrial location decision, IT effect can also be different between the two patterns. The major focus of the discussion in this paper is 
limited to the IT impact on the urban economic spatial structure: location/distribution of establishments.

One of the most comprehensive reviews on the new technology as well as its impact on urban form is found in Atkinson (1998). He noted that while there is an obvious influence of IT on urban form, the extent to which it alters the location of industry and employment is decided by three factors: (1) cost effectiveness in transformation of functions into electronic flows, (2) dependence on spatial proximity to suppliers and customers, and (3) significance of current urban advantages. Especially focusing on urban manufacturing, he also mentioned that overall pattern will be dispersed due to transportation and communication technologies from the urban core and inner suburb to outer suburb and exurban area. According to the author, there are, however, reasons for some manufacturing activities to remain in urban areas. For those sectors, the IT impact also remains limited. A more theoretical review on this relationship can be obtained from Audirac (2002). She identified two different theory groups approaching to this issue: decentralization school based on the neoclassical approach and restructuring school based on the structural approach. Even if interpretation of the mechanism was different, both of the schools agreed that IT with automobile synergy rather than the sole influence of IT has been more influential and the expected urban form is more similar to polycentric rather than monocentric.

As is the case of transportation technology, it is not surprising that IT has been acknowledged as a facilitator of dispersion of urban activities by many scholars. Gordon and Richardson (1997) was one of them. They conjectured that such technology leads to a dispersion of urban activities, possibly up to the stage where "geography is irrelevant." 
In a similar context, Drucker (1989) also noted that office work instead of workers will move around through information network. Some of the early attempts to establish a theoretical model to explain the IT impact are found in a few works of Kutay (1986a, 1986b, 1988). While the two earlier papers focused more on the models of office location and the impact of IT, a more generalized approach dealing with a model of the urban systems was featured in the third paper. The findings suggested that IT would lead to an increased level of economic disadvantage in the center and, as a result, decentralization of activities. Such decentralization of many economic activities is towards the edge cities in an intrametropolitan context and towards the lower-tier cities in urban systems in which they can avoid agglomeration diseconomies. Some recent research has attempted to combine theoretical frameworks with empirical evidence (for example, Shen, 1999; 2000). He devised an adjusted accessibility measure to incorporate location, transportation and telecommunication for employment opportunities (Shen, 1999) as well as other types of opportunities (Shen, 2000). The result showed that geographic location becomes less and less important whereas transportation and, in recent years, telecommunication factors have been more significant. Especially focusing on firms as a consumer of intermediate goods, Fujita and Hamaguchi (2001) revealed from their theoretical model that firms can be more dispersed with better-developed transportation and communication infrastructure as in the example of many developed countries. The decentralization tendency may continue in the information society as far as firms prefer the optimal places in terms of connectivity rather than proximity (Hajer and Zonneveld, 2000). Considering that IT has both centralizing and decentralizing pressure (Lusht and Farber, 1996), it is worth attempting to separate the dispersion impact from the other with 
a more specified target. One example of this type of attempt is the industrial organizational approach. Some functions related to central control have different reactions to the IT influence than more routinized functions. An emergence of back office activities located remotely from the core organization is an example of such difference (Richardson and Gillespie, 1996).

Some researchers criticize the optimistic view of the new technology. There exists a gap, according to Capello (1994), between the introduction of new IT and changes in the spatial pattern of firms. This misconception is ascribed to overestimation of the technological potential and to optimistic and superficial analyses on the relationship between the new technology and spatial restructuring. Rather, the general expectation that IT induces dispersion cannot be realized due to several constraints. Poole and Samuels (1994) identified five possible reasons that hinder the dispersion of economic activities: (1) industrial inertia, (2) local market orientedness, (3) advantage of flexible specialization, (4) closeness to consumers, and (5) closeness to cheaper labor pool. The need for face-to-face contact seems to be another factor that binds some types of firms at a closer location. Gasper and Glaeser (1998) focused on the relationship between IT and face-to-face interaction and/or cities that facilitate those interactions. In the empirical analysis using telephone call data, they concluded that those two are complements rather than substitutes, reflecting that centralizing forces in cities do not seem to vanish. Among many types of industries, Markusen and Gwisada (1993) showed that especially hightechs and producer services prefer to stay geographically close to manufacturing activities, so that IT does not have such dispersion effect at least on manufacturing. Arguing against the optimistic view of technology, Salomon (1996) suggested that there 
are four assumptions underlying the proposition that cities will disperse due to IT: (1) substitutive relationship between transportation and telecommunication, (2) substitution of information for material goods, (3) ubiquity of telecommunications, and (4) the recognition that dispersal has been constrained by congestion and travel costs. At a more conceptual model, geography and distribution of economic activities can be redefined on the basis of information flows. Echeverri-Carroll (1996) implied that network connectivity is more important factor in deciding distribution pattern than physical distance. The author did not, however, agree that the technology neutralizes the distance decay effect in the sense that these technologies impose higher investments on inter-firm linkages and more stringent restrictions on labor skills and flexibility that constrain the freedom of location decisions.

There are also studies that lie in the middle of the spectrum in the debate, suggesting a mixed influence from the new technology. Exploring the effect of a more broadly defined computer technology on location pattern of economic activities, Peitchinis (1992) summarized distributional features as a global dispersion of production process, but, at the same time, a spatial concentration of management. In the paper that examines IT impact on cities, Moses (1998) also argued that both concentration and dispersion are probable in the future. Lusht and Farber (1996) suggested that even if decentralization force becomes more important under the influence of the new technology, there are still several factors that drive concentration of activities such as (1) reduced congestion due to flexible working hours, (2) other pollution/congestionreducing technology, (3) necessity of central control on dispersed production and distribution functions, (4) uneven distribution of IT facilities, and (5) need for face-to- 
face contact. Yen and Mahmassani (1997) identified two aspects of office location decisions by organizations in assessing the impact of IT: (1) the need to locate where there is access to telecommunication networks and (2) an increased opportunity to locate where infrastructure cost is lower than traditional office locations such as downtown areas. These two conditions, however, still impose another type of concentration pressure. In other words, it will be a dispersion if activities move away from the CBD to outer regions. However, location of firms may have to be confined in limited areas with IT infrastructure, which may lead to "dispersed concentration" in the short run until the technology becomes ubiquitous.

\section{Empirical analysis framework}

The main focus of the paper is on the spatial distribution pattern of manufacturing sectors. Table 1 shows the list of manufacturing sectors chosen and analyzed in the empirical analysis. In general, these sectors may have a higher level of industrial backward and forward linkages with other sectors and, as a result, be thought of as having a higher dependency on IT due to communication needs than other sectors.

\section{< Insert table 1 here $>>$}

The first part of the analysis examines the temporal trend of the growth of IT infrastructure and the overall level of dispersion of the selected manufacturing activities in the area. By tracing this trend, an answer can be provided to such a question if IT 
either induces concentration/dispersion or does not have a great influence on distribution pattern.

Since it is hard to obtain a direct measure of the level of IT infrastructure, a surrogate index is used in the analysis: the number of information intensive establishments (Tofflemire, 1992; Sohn, et al., 2002). The logic behind this measure is that a higher level of IT infrastructure is expected as the number of information intensive establishments increases. If more detailed data sets are available, information intensive establishment can be defined in a more precise way as in the studies of Sinden (1995) and Moulaert and Djellal (1995) where, for example, British SIC 7902 (telecommunications) and French NAE 7703 (information technology and organization consulting sector) and 7704 (computer services) were adopted. In many cases, however, such detailed information is not usually obtained, especially when performing an analysis at a more disaggregate geographic scale (ZIP Code zones as a unit area, for example). In a similar situation, Tofflemire (1992) used U.S. SIC 6000 (F.I.R.E.), 73 (business services), 81 (legal services), and 87 (engineering, accounting and management services) as a group of information intensive sectors. Sohn, et al. (2002) applied SIC 73, 81, and 87 to their empirical research on Chicago. Information intensive establishments in this analysis are composed of the establishments in SIC 6000, 73, 81 and 87.

Level of dispersion can be measured by two sets of indices which are complementary with each other: locational Gini and Moran's I. 
$G_{k}=\frac{\frac{1}{n(n-1)} \sum_{i=1}^{n} \sum_{j=1}^{n}\left|x_{i}-x_{j}\right|}{4 \overline{\mu_{x}}}$

where

$n=$ number of ZIP Code zones

$x_{i(j)}=\frac{\text { ZIP Code zone } i \text { 's }(j \text { 's) employment (establishment) share in sector } k}{\text { ZIP Code zone } i \text { 's }(j \text { 's) total employment share }}(i \neq j)$

$\overline{\mu_{x}}=\frac{\sum_{i=1}^{n} x_{i}}{n}$

The locational Gini coefficient in equation (1) was first introduced by Krugman (1991) to examine the relative spatial concentration of the U.S. industries. ${ }^{1}$ While the traditional Gini coefficient focuses on the relative concentration pattern of a certain economic sector in relation to other sectors in the same zone, locational Gini considers the relative concentration pattern of a centain economic sector in a zone in relation to the same sector in other zones. If activities are evenly distributed over zones (or the share of a certain sector equals to the total share in all zones), the coefficient becomes 0 . On the other hand, when all the activities of a certain sector are concentrated in one zone, the coefficient goes to 0.5 . Between the two numbers, a higher value implies a higher level of concentration and a lower value reflects a higher level of dispersion. This index in this analysis is able to provide such information on whether a large number of establishments are concentrated in a small number of ZIP Code zones or not.

One of the drawbacks of the locational Gini coefficient, however, is that it does not provide any information on geographic al distribution pattern of activities of interest. In other words, with a higher locational Gini coefficient, we know that a certain

\footnotetext{
${ }^{1}$ Notations of the equation are borrowed from Kim, et al. (2000).
} 
economic activity is concentrated in a limited number of ZIP Code zones rather than distributed evenly all over the zones. However, it does not tell us whether those limited number of zones are spatially concentrated or just randomly distributed. If the latter is the case, it may not be considered as a spatial concentration at a multi ZIP Code zonal level even if it is at a single ZIP Code zonal level. In this respect, Moran's I can be used as a complimentary statistic to check the spatial concentration of activities at an interzonal level. $^{2}$

$I=\left(n / S_{0}\right) \sum_{i=1}^{n} \sum_{j=1}^{n} w_{i j}\left(x_{i}-\overline{\mu_{x}}\right)\left(x_{j}-\overline{\mu_{x}}\right) / \sum_{i=1}^{n}\left(x_{i}-\overline{\mu_{x}}\right)^{2}$

where

$S_{0}=\sum_{i=1}^{n} \sum_{j=1}^{n} w_{i j}$

$w_{i j}=$ element in the spatial weights matrix corresponding to the observation pair $i, j$

Moran's $I$ has a very similar equation structure to the one for correlation coefficient. For example, correlation coefficient is covariance over the product of variances of each variable. Under certain conditions, ${ }^{3}$ Moran's $I$ is reduced to the product of deviation of each observation pair from the mean over the variance of the variable. The difference is that the latter deals with one variable (as opposed to two variables in the former) and spatial weight matrix literally works to define different weights for different distance sets in the latter equation. Similar to correlation coefficient, the range of the coefficient is approximately between -1 and 1. A positive coefficient implies positive

\footnotetext{
2 The equation for Moran's I is drawn from Anselin (1995b).

${ }^{3}$ When spatial weight matrix is row-standardized, the scaling constant $S_{0}$ becomes equal to $N$, replacing $N / S_{0}$ with 1.
} 
autocorrelation and a negative value indicates negative autocorrelation. ${ }^{4} \mathrm{~A}$ more concentrated pattern is expected with a higher $I$ and a more dispersed pattern with a lower I.

The second part of the analysis more focuses on the distribution pattern at a micro geographic scale. A regression model is established to explain a possible influence of IT infrastructure on location pattern of establishments in the selected manufacturing sectors at a local scale. Distribution pattern around a certain zone, rather than activity level (number of establishments) in the zone, is used as the dependent variable to account for a broader range of impact area. This pattern can be measured by a local indicator of spatial association (LISA) (Anselin, 1995a). For the purpose of this analysis, $G_{i}{ }^{*}$ statistic is calculated by each ZIP Code zone and used as the dependent variable in the model.

$$
G_{i}^{*}=\frac{\sum_{j} w_{i j} x_{j}-W_{i}^{*} \bar{x}}{s\left\{\left[\left(n S_{1 i}^{*}\right)-W_{i}^{* 2}\right] /(n-1)\right\}^{1 / 2}}, \quad \text { all } j
$$

where

$x_{j}=$ observation in $j$

$W_{i}^{*}=\sum_{j} w_{i j}$

$\bar{x}=\frac{\sum_{j} x_{j}}{(n-1)}$

$s=\sqrt{\frac{\sum_{j}\left(x_{j}-\bar{x}\right)^{2}}{(n-1)}}$

$n=$ number of ZIP Code zones

$S_{1 i}^{*}=\sum_{j} w_{i j}^{2}$

\footnotetext{
${ }^{4}$ Since the expected value of $I$ is not exactly zero, it should be stated that positive autocorrelation prevails with $I$ greater than expected value and vice versa. However, as sample size grows up, the expected value of I converges to zero.
} 
It is first developed by Getis and Ord (1992) and later revised by Ord and Getis (1995). The uniqueness of this statistic is that positive and significant $z$ value for $G_{i}{ }^{*}$ statistic indicates a spatial clustering of high values, whereas negative and significant $\mathrm{z}$ value indicates a spatial clustering of low values (Anselin, 1995b, p. 23-2). By investigating these statistics in association with the IT variable in the regression, the analysis is able to reveal whether the IT factor is significant in explaining the spatial distribution pattern of urban manufacturing activities. A positive coefficient of the IT variable in the regression shows that IT infrastructure works as an attraction force to manufacturing activities and the corresponding distribution is considered to be concentrated whereas a negative coefficient implies repellence of activities and dispersed distribution.

Table 2 lists a set of independent variables to be used in the regression models. The first variable is the level of IT in a certain ZIP Code zone represented by the number of establishments in the information intensive sectors explained earlier. The second set of variables is for measuring the centrality of manufacturing activities. Two variables considered here are the average distance from the major city centers (Washington D.C. and Baltimore) and establishment density of each ZIP Code zone. If a certain zone is located closer to the major city centers, it has a higher probability of taking advantage of the externalities that the centers provide. While the distance variable only counts on the influence form the city centers, establishment density can account for the impact of city subcenters as well. The third group of variables is to examine accessibility. Two variables used here are the average distance from the three major airports (Baltimore-Washington International (BWI), Reagan Washington National (DCA), and Washington Dulles 
International (IAD)) and highway dummy: 1 if interstate highway passes a certain ZIP Code zone and 0 otherwise. The last independent variable is population both as a product market as well as a source of labor force.

< Insert table 2 here $>>$

\section{Information technology impact in the Washington-Baltimore CMSA}

There are 479 ZIP Code zones in the Washington Baltimore CMSA used in the empirical analysis. Figure 1 provides an overview of the area. All the economic-related variables are extracted from the 1994 to 1997 ZIP Code Business Patterns. Population is obtained from the 1990 Population Census.

$<$ Insert figure 1 here $>>$

Figure 2 shows the change of the locational Gini coefficients for the five sectors along with the change of the information infrastructure index measured by the total number of establishments in the information intensive sectors defined in the previous section. The 1994 number of establishments is set as $100 \%$ and the trend shows that the index has increased over the years. With some variations, the locational Gini coefficient has decreased along with the increase of the information infrastructure index. The negative slope of the lines reflects that establishments are spatially dispersed at a higher degree as a higher level of information infrastructure is provided. This result complies 
with the dispersion hypothesis of IT in the earlier section. Even if different sectors show slightly different trends over the years, it is hard to determine which sector has been more sensitive to the change of the infrastructure index and which sector has been more dispersed than others.

\section{$<$ Insert figure 2 here $>>$}

The result in figure 2 reveals the dispersion trends of establishments among 479 ZIP Code zones. This does not, however, inform whether such dispersion occurs towards their neighboring ZIP Code zones or the zones at a farther location. If the former is the case, it may not be viewed as a substantial dispersion even if a lowered level of the locational Gini coefficient is observed. In other words, while a cluster of ZIP Code zones with a higher number of establishments should also be considered to be a concentration, the coefficient is not able to detect this type of concentration In addition, considering that there is no reason to expect economic behavior to conform artificially determined areal units (Anselin and Bera, 1998), it is necessary to examine distribution pattern in different spatial contexts to complete the analysis. Moran's $I$ is a complementary statistic to the locational Gini coefficient in this respect.

Figure 3 presents the change of Moran's $I$ in association with the change of the infrastructure index. With the exception that SIC 28 (chemicals and applied products) shows a decrease and SIC 35 (industrial machinery and equipment) reveals a mild decrease, all three sectors have remained insensitive to the information infrastructure. The stability of the coefficient regardless of the increase in the information infrastructure 
index implies that the distribution pattern at a multi ZIP Code zone level is not influenced by the infrastructure index. The decreasing coefficients, as in the case of SIC 28 and 35, on the other hand, reflect that more dispersion and, as a result, smaller clusters of ZIP Code zones are expected across the area over the years. Overall, SIC 27 (printing and publishing) and 35 have maintained a relatively high level of concentration of activities and the other three sectors show a lower level of concentration.

\section{$<$ Insert figure 3 here $>>$}

The two results on coefficient of dispersion/concentration can be interpreted jointly. The decrease in the locational Gini coefficient along with the increase in the information infrastructure index and the stability of Moran's I reflect that dispersion of establishments occurs from one ZIP Code zone to another and such dispersion may be towards both neighboring and farther zones. The decrease of the locational Gini coefficient and the decrease of Moran's I imply that dispersion occurs from one zone to another that is farther away. In either case, overall trend is concluded as dispersion.

While figure 2 and 3 show a dispersion of establishments along with the increase in information infrastructure in an urban area as a whole, intrametropolitan location pattern also needs to be examined using a set of regression models and the corresponding IT coefficients. Table 3 through 7 list the regression result of the five sectors for four years between 1994 and 1997. Briefly summarizing other coefficients than IT, CBD mostly shows negative signs reflecting that closeness either to the D.C. or downtown Baltimore is an important location factor. EDENSITY is positive, so that centers in an 
urban area including subcenters might be an attractive location of establishments. AIRPORT is positive, implying that proximity to the airports is not a significant factor. One explanation on this is that airplanes may not be considered to be a proper transportation mode for many manufacturing products considering that outputs are heavy in many cases. The positive sign of $H I G H W A Y$ reassures this speculation implying that establishments prefer to stay near highways. POPULATION as a product and a labor market has remained significant in location decision of establishments. ${ }^{5}$

\section{< Insert table 3 to 7 here >>}

Figure 4 summarizes temporal change of the IT coefficients in the regression model for the five sectors. The positive signs of SIC 27 and SIC 36/38 (Electronic, electric, and computer equipment) reflect that more establishments tend to concentrate and make a cluster around as information infrastructure expands in a certain ZIP Code zone. Considering that those sectors might require intensive computer technology and network linkage for operation of their businesses, it is not surprising to observe this pattern of the impact. The other three sectors, on the other hand, show a negative sign implying that they prefer to stay away from the zone with a higher level of information infrastructure. One explanation is that those activities may be relatively less dependent on the new technology, so that they are able to reduce production cost by locating themselves outside the beneficiary area of such infrastructure (for cheaper rent) and avoiding, either direct or indirect, externality cost: agglomeration diseconomies such as

\footnotetext{
${ }^{5}$ Exceptions should also be noted that SIC 27 is positive on CBD and negative on AIRPORT. SIC 36 and 38 is negative on both EDENSITY and POPULATION. SIC 37 is negative on HIGHWAY.
} 
congestion cost and severe competition with other businesses on local product and labor markets.

\section{$<$ Insert figure 4 here $>>$}

Regardless of the sign of the IT coefficient, all the sectors have shown an increase in magnitude of the coefficient, suggesting that information infrastructure as a location factor has become more significant over the years. In the case of the positive coefficients, it is straightforward that bigger coefficient means higher dependence of location patterns of establishments on information infrastructure. Increase of negative coefficients (decrease in absolute terms) over the years is related to a reduced level of repellence and, as a result, an increased level of attraction to some extent. This is a result contradictory to the previous findings based on the (distribution pattern) analysis on an urban area as a whole. What is implied from this set of analyses is that the concentration/dispersion hypothesis can be both right and wrong depending on spatial context of analysis. Dispersion might be obvious from the influence of information infrastructure at a metropolitan level (in the distributional context). At the same time, however, concentration effect of IT might still be dominant at an intrametropolitan scale (in the locational context) as the case here in the Washington-Baltimore CMSA. It suggests that a proper proposition of the IT impact on urban economic spatial structure be associated with the corresponding spatial scale of the analysis: global (distributional) or local (locational). 


\section{Conclusions and policy implications}

This paper started with the question if IT has a dispersion/concentration effect on the spatial distribution of some selected manufacturing activities in an urban area. The Washington-Baltimore CMSA with 479 ZIP Code zones was analyzed through two steps of empirical analysis. The first analysis using locational Gini coefficient and Moran's I focused on distribution pattern for the urban area as a whole and found that dispersion was prominent. The second part of the analysis using $G_{i}{ }^{*}$ statistic as the dependent variable in the regression model, however, showed that IT has induced more concentration rather than dispersion at an intrametropolitan scale, revealing a discrepancy between the results of the two analyses on IT impact on distribution pattern depending on spatial scale of analysis: global (distributional) and local (locational).

One of the issues related to implementation of IT policies in an urban area is that IT may not work as a facilitator of dispersion of economic activities as the optimistic view forecasts based on what the technology can do for society. Such causality suggested by the optimist may be realized only in the long run when IT becomes ubiquitous. At least for the time being, until it comes true, however, IT infrastructure itself shows uneven spatial distribution pattern and may work as a locational attractiveness of a certain zone to economic activities. In other words, a policy measure designed to work for dispersion might actually work towards the other way around. Related to this is the relevant spatial scale of policies. If the policy focuses on metropolitan scale (in the distributional context), increasing investment on information infrastructure might lead to a higher level of dispersion as a whole. The IT policy within a metropolitan area (in the 
locational context), however, should be implemented with more care in that it may induce spatial agglomeration of economic activities around the zone in which the infrastructure has been improved. As far as the distribution of IT is uneven, location and distribution of economic activities may be influenced in a positive way (attraction factor) by the location and distribution of the IT infrastructure. Urban spatial policy related to IT impact, in this context, should consider both location and distribution patterns in a simultaneous way. In a sense, substantial dispersion of economic activities in an urban area could be achieved by inducing decentralization of such IT infrastructure over the area.

One of the extensions of the paper is to apply the model to a different spatial scale of the area such as county and/or state to understand the influence of IT in a different spatial context. Examining a longer time series is another extension of the analysis for understanding the long run trends of urban economic spatial structure associated with IT impact. Finally, extracting more direct measurement on the level of information infrastructure than the number of information intensive establishments used here and some other papers has been and will be a challenging task, but with priority. 


\section{Reference}

Anselin L (1995a) Local indicators of spatial association-LISA. Geographical Analysis 27: 93-115.

Anselin L (1995b) Spacestat version 1.80 user's guide. Regional Research Institute, West Virginia University, Morgantown.

Anselin L, Bera AK (1998) Spatial dependence in linear egression models with an introduction to spatial econometrics. In: Ullah A, Giles DEA (eds) Handbook of applied economic statistics. Marcel Dekker, New York.

Atkinson RD (1998) Technological change and cities. Cityscape 3: 129-70.

Audirac I (2002) Information technology and urban form. Journal of Planning Literature 17: forthcoming.

Capello R (1994) Towards new industrial and spatial systems: the role of new technologies. Papers in Regional Science 73: 189-208.

Coffey WJ (2000) The geographies of producer services. Urban Geography 21: 170-83.

Drucker PF (1989) Information and the future of the city. Urban Land 48: 38-9.

Echeverri-Carroll EL (1996) Flexible production, electronic linkages, and large firms: evidence from the automobile industry. Annals of Regional Science 30:135-52.

Fujita M, Hamaguchi N (2001) Intermediate goods and the spatial structure of an economy. Regional Science and Urban Economics 43: 136-56.

Gaspar J, Glaeser EL (1998) Information technology and the future of cities. Journal of Urban Economics 43: 136-56.

Getis A, Ord JK (1992) The analysis of spatial association by use of distance statistics. Geographical Analysis 24: 189-206.

Gordon P, Richardson HW (1997) Are compact cities a desirable planning goal? Journal of the American Planning Association 63:95-106.

Hajer M, Zonneveld W (2000) Spatial planning in the network society: rethinking the principles of the planning in the Netherlands. European Planning Studies 8: 33755. 
Kim Y, Barkley DL, Henry MS (2000) Industry characteristics linked to establishments concentrations in nonmetropolitan areas. Journal of Regional Science 40: 231-59.

Krugman P (1991) Geography and trade. MIT Press, Cambridge.

Kutay A (1986a) Effects of telecommunications on office location Urban Geography 7: 243-57.

Kutay A (1986b) Optimum office location and the comparative statics of information economies. Regional Studies 20: 551-64.

Kutay A (1988) Technological change and spatial transformation in an information economy: 2. the influence of new information technology on the urban system. Environment and Planning A 20: 707-18.

Lusht KM, Farber D (1996) Information technology and urban structure. Real Estate Finance 13: 13-20.

Markusen AR, Gwisada V (1993) Multipolarity and the layering of functions in world cities: New York City's struggle to stay on top (Working Paper 55). Center for Urban Policy Research, State University of New Jersey, Piscataway.

Moss ML (1998) Technology and cities. Cityscape 3: 107-27.

Moulaert F, Djellal F (1995) Information technology consultancy firms: economies of agglomeration from a wide-area perspective. Urban Studies 32: 105-22.

Ord JK, Getis A (1995) Local spatial autocorrelation statistics: distributional issues and an application Geographical Analysis 27: 286-306.

Peitchinis SG (1992) Computer technology and the location of economic activity. Futures 24: 813-20.

Poole KE, Samuels C (1994) Manufacturing trends in America's larger cities. In: Urban Manufacturing: Dilemma or Opportunity? National Council for Urban Economic Development, Washington DC.

Richardson R, Gillespie A (1996) Advanced communications and employment creation in rural and peripheral regions: a case study of the highlands and islands of Scotland. Annals of Regional Science 30:91-110.

Salomon I (1996) Telecommunications, cities and technological opportunities. Annals of Regional Science 30: 75-90.

Shen Q (1999) Transportation, telecommunications, and the changing geography of opportunity. Urban Geography 20:334-55. 
Shen Q (2000) An approach to representing the spatial structure of the information society. Urban Geography 21: 543-60.

Sinden A (1995) Telecommunications services: job loss and spatial restructuring in Britain, 1989-1993. Area 27:34-45.

Sohn J, Kim TJ, Hewings GJD (2002) Information technology impacts on urban spatial structure in the Chicago region. Geographical Analysis 34: 313-29.

Tofflemire JM (1992) Telecommunication external economies, city size and optimal pricing for telecommunications. Journal of Regional Science 32: 77-90.

Yen J-R, Mahmassani HS (1997) Telecommuting adoption: conceptual framework and model estimation. Transportation Research Record 1606: 95-102. 
Table 1. Manufacturing sectors considered in the analysis

\begin{tabular}{|l|l|}
\hline SIC & Description \\
\hline 27 & Printing and publishing \\
\hline 28 & Chemicals and allied products \\
\hline 35 & Industrial machinery and equipment \\
\hline 36 and 38 & Electronic, electric and computer equipment \\
\hline 37 & Transportation equipment \\
\hline
\end{tabular}

Table 2. Independent variables in the regression models

\begin{tabular}{|l|l|l|}
\hline Group & Variable & Description \\
\hline IT impact & IT & $\begin{array}{l}\text { Number of establishments in the information } \\
\text { intensive sectors }\end{array}$ \\
\hline Centrality & CBD & $\begin{array}{l}\text { Average distance (mile) from the major city } \\
\text { centers (Washington D.C. and Baltimore) }\end{array}$ \\
\cline { 2 - 3 } & EDENSITY & Total establishment density per square mile \\
\hline Accessibility & AIRPORT & $\begin{array}{l}\text { Average distance (mile) from the three major } \\
\text { airports (BWI, DCA and IAD) }\end{array}$ \\
\cline { 2 - 3 } & HIGHWAY & Highway dummy \\
\hline Market/labor force & POPULATION & Population \\
\hline
\end{tabular}

Table 3. Regression results: printing and publishing (SIC 27)

\begin{tabular}{|l|l|l|l|l|}
\hline Variables & 1994 & 1995 & 1996 & 1997 \\
\hline Constant & 2.29999 & 2.39769 & 2.36062 & 2.33565 \\
& $(.1727)^{* * *}$ & $(.1740)^{* * *}$ & $(.1724)^{* * *}$ & $(.1750)^{* * *}$ \\
\hline IT & .00063 & .00073 & .00079 & .00091 \\
& $(.0005)$ & $(.0005)$ & $(.0004)^{*}$ & $(.0004)^{* *}$ \\
\hline CBD & .06039 & .08440 & .08504 & .11339 \\
& $(.0150)^{* * *}$ & $(.0151)^{* * *}$ & $(.0150)^{* * *}$ & $(.0152)^{* * *}$ \\
\hline EDENSITY & .00078 & .00076 & .00078 & .00080 \\
& $(.0001)^{* * *}$ & $(.0001)^{* * *}$ & $(.0001)^{* * *}$ & $(.0001)^{* * *}$ \\
\hline AIRPORT & -.13160 & -.15821 & -.15690 & -.18484 \\
& $(.0159)^{* * *}$ & $(.0160)^{* * *}$ & $(.0159)^{* * *}$ & $(.0161)^{* * *}$ \\
\hline HIGHWAY & .35959 & .33199 & .34150 & .31123 \\
& $(.1182)^{* * *}$ & $(.1187)^{* * *}$ & $(.1172)^{* * *}$ & $(.1188)^{* * *}$ \\
\hline POPULATION & .00003 & .00003 & .00003 & .00002 \\
& $(.000004)^{* * *}$ & $(.000004)^{* * *}$ & $(.000004)^{* * *}$ & $(.000004)^{* * *}$ \\
\hline Adjusted ${ }^{2}$ & .6618 & .6683 & .6587 & .6539 \\
\hline
\end{tabular}

$* * * 99 \% * * 95 \% * 90 \%$, standard error in parenthesis 
Table 4. Regression results: chemicals and allied products (SIC 28)

\begin{tabular}{|l|l|l|l|l|}
\hline Variables & 1994 & 1995 & 1996 & 1997 \\
\hline Constant & .14974 & .13672 & .24651 & .27515 \\
& $(.1725)$ & $(.1678)$ & $(.1622)$ & $(.1606)^{*}$ \\
\hline IT & -.00094 & -.00093 & -.00058 & -.00066 \\
& $(.0005)^{* *}$ & $(.0005)^{* *}$ & $(.0004)$ & $(.0004)^{*}$ \\
\hline CBD & -.35207 & -.32794 & -.30011 & -.28436 \\
& $(.0150)^{* * *}$ & $(.0146)^{* * *}$ & $(.0141)^{* * *}$ & $(.0139)^{* * *}$ \\
\hline EDENSITY & .00029 & .00027 & .00018 & .00017 \\
& $(.0001)^{* *}$ & $(.0001)^{* *}$ & $(.0001)$ & $(.0001)$ \\
\hline AIRPORT & .34765 & .32355 & .29346 & .27697 \\
& $(.0159)^{* * *}$ & $(.0154)^{* * *}$ & $(.0149)^{* * *}$ & $(.0148)^{* * *}$ \\
\hline HIGHWAY & .36169 & .36789 & .31073 & .32491 \\
& $(.1181)^{* * *}$ & $(.1145)^{* * *}$ & $(.1103)^{* * *}$ & $(.1090)^{* * *}$ \\
\hline POPULATION & .00002 & .00002 & .00002 & .00002 \\
& $(.000004)^{* * *}$ & $(.000004)^{* * *}$ & $(.000004)^{* * *}$ & $(.000004)^{* * *}$ \\
\hline Adjusted R & .5986 & .5822 & .5568 & .5399 \\
\hline
\end{tabular}
$* * * 99 \% * * 95 \% * 90 \%$, standard error in parenthesis

Table 5. Regression results: industrial machinery and equipment (SIC 35)

\begin{tabular}{|l|l|l|l|l|}
\hline Variables & 1994 & 1995 & 1996 & 1997 \\
\hline Constant & .05411 & -.01769 & -.13137 & -.03563 \\
& $(.1899)$ & $(.1892)$ & $(.1870)$ & $(.1890)$ \\
\hline IT & -.00111 & -.00087 & -.00052 & -.00058 \\
& $(.0005)^{* *}$ & $(.0005)^{*}$ & $(.0005)$ & $(.0005)$ \\
\hline CBD & -.45539 & -.42771 & -.41658 & -.43928 \\
& $(.0165)^{* * *}$ & $(.0164)^{* * *}$ & $(.0162)^{* * *}$ & $(.0164)^{* * *}$ \\
\hline EDENSITY & .00023 & .00020 & .00015 & .00013 \\
& $(.0001)^{*}$ & $(.0001)$ & $(.0001)$ & $(.0001)$ \\
\hline AIRPORT & .45442 & .42887 & .42106 & .44251 \\
& $(.0175)^{* * *}$ & $(.0174)^{* * *}$ & $(.0172)^{* * *}$ & $(.0174)^{* * *}$ \\
\hline HIGHWAY & .47505 & .48298 & .45539 & .39117 \\
& $(.1299)^{* * *}$ & $(.1291)^{* * *}$ & $(.1271)^{* * *}$ & $(.1283)^{* * *}$ \\
\hline POPULATION & .00002 & .00002 & .00001 & .00001 \\
& $(.00001)^{* * *}$ & $(.00001)^{* * *}$ & $(.00001)^{* * *}$ & $(.00001)^{* * *}$ \\
\hline Adjusted ${ }^{2}$ & .6609 & .6290 & .6142 & .6322 \\
\hline
\end{tabular}

$* * * 99 \% * * 95 \% * 90 \%$, standard error in parenthesis 
Table 6. Regression results: electronic, electric and computer equipment (SIC 36 and 38)

\begin{tabular}{|l|l|l|l|l|}
\hline Variables & 1994 & 1995 & 1996 & 1997 \\
\hline Constant & 1.21946 & 1.164 & 1.19245 & 1.27956 \\
& $(.2120)^{* * *}$ & $(.2092)^{* * *}$ & $(.2182)^{* * *}$ & $(.2205)^{* * *}$ \\
\hline IT & .00162 & .00171 & .00193 & .00229 \\
& $(.0006)^{* * *}$ & $(.0006)^{* * *}$ & $(.0006)^{* * *}$ & $(.00054)^{* * *}$ \\
\hline CBD & -.14696 & -.14477 & -.11548 & -.09582 \\
& $(.0185)^{* * *}$ & $(.0182)^{* * *}$ & $(.0189)^{* * *}$ & $(.0191)^{* * *}$ \\
\hline EDENSITY & -.00046 & -.00044 & -.00052 & -.00060 \\
& $(.0002)^{* * *}$ & $(.0001)^{* * *}$ & $(.0002)^{* * *}$ & $(.0001)^{* * *}$ \\
\hline AIRPORT & .11630 & .11487 & .08608 & .06423 \\
& $(.0195)^{* * *}$ & $(.0192)^{* * *}$ & $(.0201)^{* * *}$ & $(.0203)^{* * *}$ \\
\hline HIGHWAY & .39353 & .43285 & .41386 & .37518 \\
& $(.1451)^{* * *}$ & $(.1427)^{* * *}$ & $(.1483)^{* * *}$ & $(.1497)^{* *}$ \\
\hline POPULATION & -.000003 & -.000003 & -.00001 & -.00001 \\
& $(.00001)$ & $(.00001)$ & $(.00001)^{*}$ & $(.00001)^{* *}$ \\
\hline Adjusted R ${ }^{2}$ & .2752 & .2818 & .2153 & .2091 \\
\hline \multicolumn{2}{|l|}{$* * * 99 \% * * 95 \% * 90 \%$, standard error in parenthesis } \\
\end{tabular}

Table 7. Regression results: transportation equipment (SIC 38)

\begin{tabular}{|l|l|l|l|l|}
\hline Variables & 1994 & 1995 & 1996 & 1997 \\
\hline Constant & .02536 & .04391 & .07387 & -.00371 \\
& $(.1762)$ & $(.1828)$ & $(.1836)$ & $(.1763)$ \\
\hline IT & -.00094 & -.00089 & -.00086 & -.00046 \\
& $(.0005)^{*}$ & $(.0005)^{*}$ & $(.0005)^{*}$ & $(.0004)$ \\
\hline CBD & -.24606 & -.24877 & -.18497 & -.17835 \\
& $(.0153)^{* * *}$ & $(.0159)^{* * *}$ & $(.0159)^{* * *}$ & $(.0153)^{* * *}$ \\
\hline EDENSITY & .00022 & .00022 & .00017 & .00010 \\
& $(.0001)^{*}$ & $(.0001)^{*}$ & $(.0001)$ & $(.0001)$ \\
\hline AIRPORT & .24676 & .25001 & .18431 & .17975 \\
& $(.0162)^{* * *}$ & $(.0168)^{* * *}$ & $(.0169)^{* * *}$ & $(.0162)^{* * *}$ \\
\hline HIGHWAY & -.02628 & -.09609 & -.08955 & -.11816 \\
& $(.1206)$ & $(.1247)$ & $(.1248)$ & $(.1197)$ \\
\hline POPULATION & .00001 & .00001 & .00001 & .00001 \\
& $(.000004)^{* *}$ & $(.00001)^{*}$ & $(.00001)^{* * *}$ & $(.000004)$ \\
\hline Adjusted ${ }^{2}$ &. .3800 & .3611 & .2386 & .2351 \\
\hline
\end{tabular}

$* * * 99 \% * * 95 \% * 90 \%$, standard error in parenthesis 


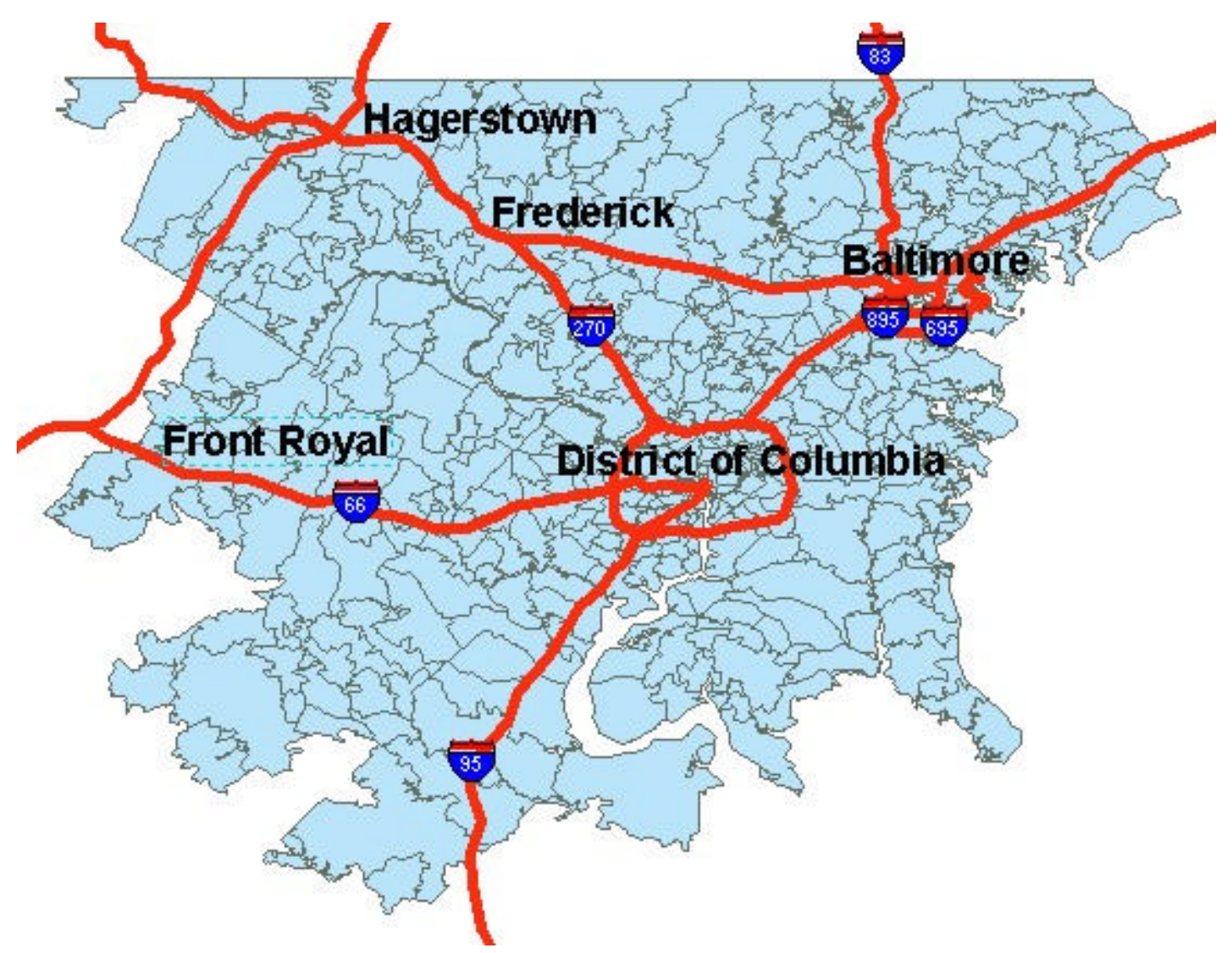

Figure 1. Washington-Baltimore CMSA

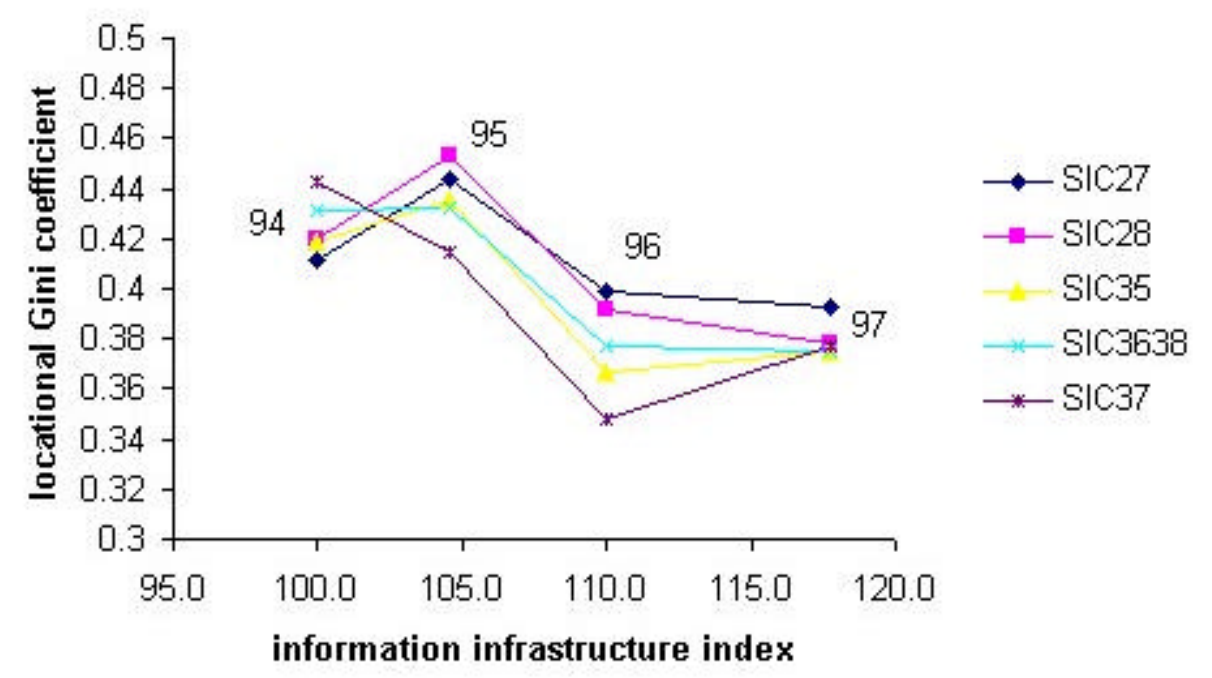

Figure 2. Information infrastructure index and locational Gini coefficient 


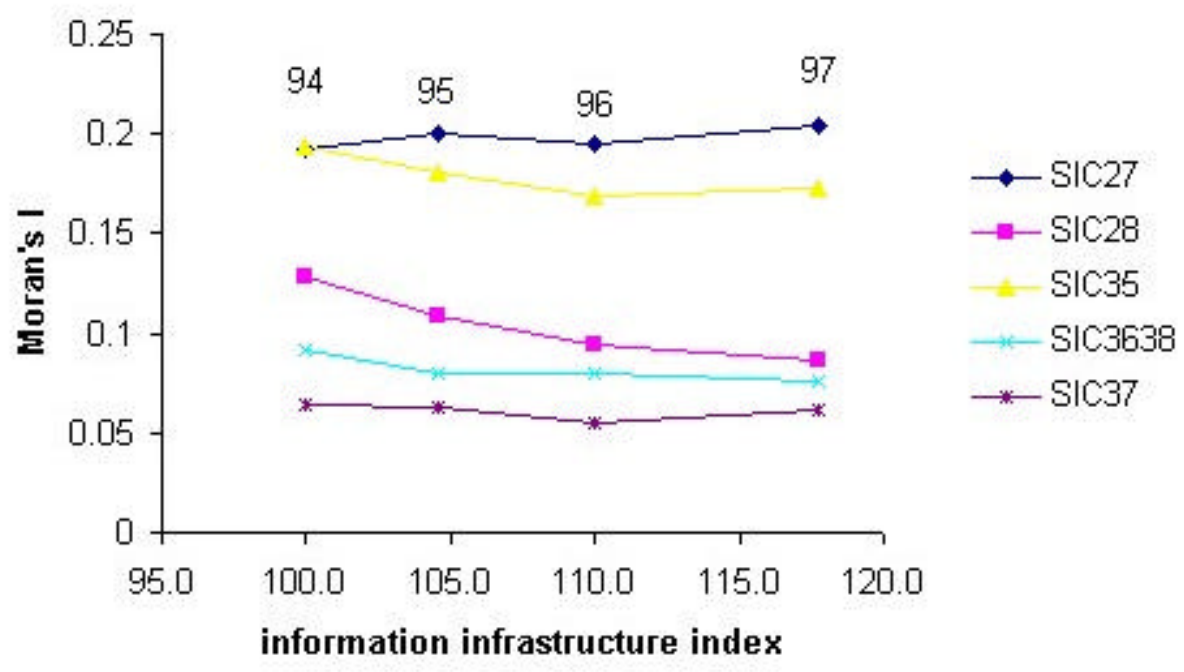

Figure 3. Information infrastructure index and Moran's I

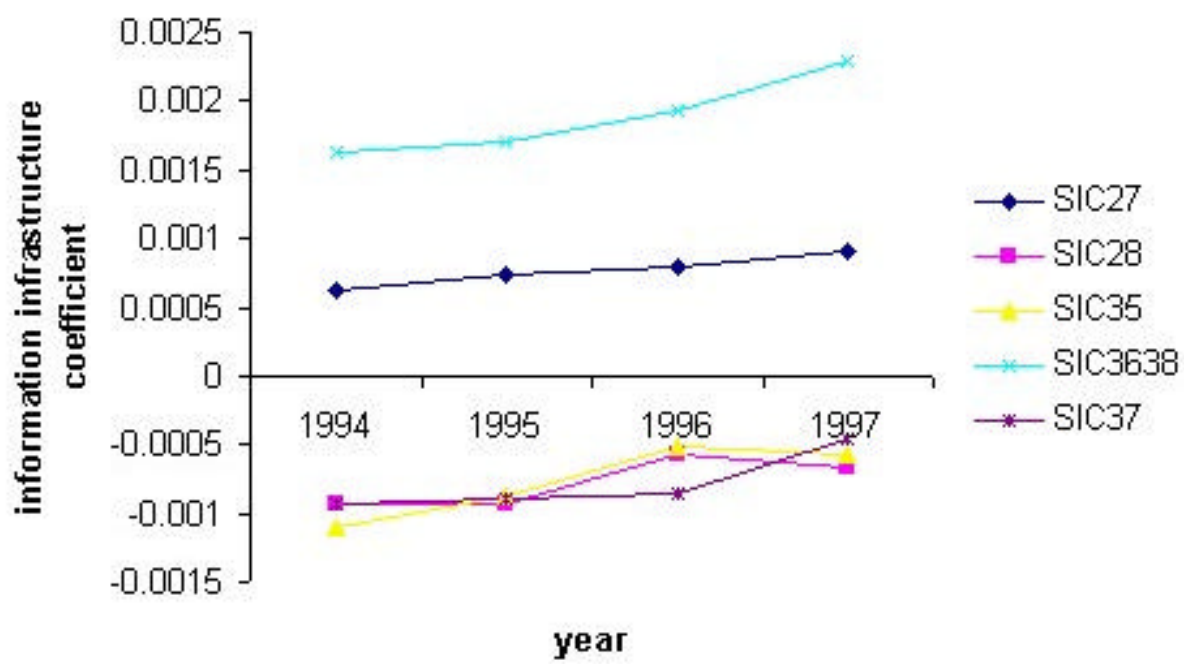

Figure 4. Temporal trends of the change of the coefficient on information infrastructure 